\title{
Algunas consideraciones acerca de la dis- tinción entre interpretación en abstracto e interpretación en concreto: Un Balance
}

\author{
Some Remarks On the Distinction Between Inter- \\ pretation in abstracto and Interpretation in concre- \\ to. A Reassessment
}

\begin{abstract}
Alessio Sardo*
Recepción: 17/02/2020

Evaluación: 10/03/2020

Recepción y aceptación final: 26/04/2020

Resumen: El objetivo del presente trabajo es delinear un balance del debate sobre el escepticismo interpretativo de Riccardo Guastini, debate publicado en el numero XI de la revista Discusiones, en el año 2012. Voy a expresar algunas ideas sobre un punto específico del debate: la distinción entre interpretación en abstracto e interpretación en concreto. Intentaré defender la siguiente tesis: la mejor reformulación de la distinción entre interpretación en abstracto e interpretación en concreto se funda en una teoría del significado que define: a) el producto de la interpretación en abstracto como el sentido de una disposición; b) el producto de la interpretación en concreto como la referencia de una norma; c) la actividad de
\end{abstract}

\footnotetext{
Alexander von Humboldt Research Fellow, Heidelberg University, Institut für Staatsrecht, Verfassungslehre und Rechtsphilosophie, Alemania. Correo electrónico: alessiosardo@ymail. com. Esta investigación ha sido financiada por la fundación Alexander von Humboldt, en el marco de un proyecto más amplio sobre originalismo, positivismo, y teorías de la interpretación. Quisiera expresar mi gratitud a la fundación Alexander von Humboldt y al Profesor Martin Borowski, mi Host en la universidad de Heidelberg. Quisiera también agradecer a Mauro Barberis, Pierluigi Chiassoni y Nicola Muffato por algunas discusiones teóricas acerca de los temas del presente ensayo. Revisión lingüística a cargo de Sara Moretton.
} 
Alessio Sardo

interpretación en concreto como una estipulación de la referencia mediante un acto de adscripción. Para defender esta tesis me apoyaré en la noción de reference-determiner elaborada por Gillian Russell.

Palabras claves: positivismo jurídico - escepticismo interpretativo - interpretación en abstracto - interpretación en concreto - teorías del significado

\begin{abstract}
The aim of this essay is to take stock of the great debate on Riccardo Guastini's interpretive skepticism, which was published on the Issue XI (2012) of the journal Discusiones. The Author will formulate a few ideas on a particular topic of the debate: the distinction between interpretation in abstracto and interpretation in concreto. The Author will argue in favor of the following claim: the best restatement of the distinction between interpretation in abstracto and interpretation in concreto is grounded on a theory of meaning that defines: a) the product of an interpretation in abstracto as the sense of a normative statement; b) the product of an interpretation in concreto as the reference of a norm; c) the activity of interpretation in concreto as a stipulation of the reference through an act of ascription. In order to defend the last claim, I will rely on the notion of reference-determiner elaborated by Gillian Russell.
\end{abstract}

Key-words: legal positivism - interpretive skepticism - interpretation in abstracto - interpretation in concreto - theories of meaning

\title{
1. Introducción
}

El objetivo del presente trabajo es delinear un balance del debate sobre el escepticismo interpretativo de Riccardo Guastini, debate publicado en el numero XI de la revista Discusiones, en el año 2012. Federico Arena, Hernán Bouvier y Pablo Navarro fueron los promotores de esta profunda discusión teórica acerca del concepto de interpretación, en la que participaron también Isabel Lifante Vidal, Lorena Ramírez Ludeña, Michel Troper, Damiano Canale, Juan Ruiz Manero y el mismo Guastini. Los temas abordados en el debate son tan amplios y complejos que sería demasiado atrevido formular comentarios generales. Por lo tanto, intentaré perseguir un fin más modesto: expresar algunas ideas sobre un punto específico del debate que fue discutido intensamente por todos los participantes, y que sigue siendo vivazmente debatido aún hoy. Me refiero a la distinción entre interpretación 
Algunas consideraciones acerca de la distinción entre interpretación en abstracto...

en abstracto e interpretación en concreto. Cabe señalar que el tema tiene una importancia central, ya que se encuentra directamente vinculado con otros asuntos claves de la teoría de Guastini: la teoría del significado presupuesta por el escepticismo moderado, los límites del marco, el espacio de la discrecionalidad judicial, la relación entre escepticismo moderado y teoría "eclética" de la interpretación ${ }^{1}$, la definición de interpretación y, finalmente, la distinción entre interpretación y construcción jurídica².

En el presente ensayo, intentaré defender la tesis siguiente: la mejor defensa de la distinción entre interpretación en abstracto e interpretación en concreto se funda en una teoría del significado que define: a) el producto de la interpretación en abstracto como el sentido de una disposición; b) el producto de la interpretación en concreto como la referencia de una norma; c) la actividad de interpretación en concreto como una estipulación de la referencia mediante un acto de adscripción.

La estructura del presente trabajo es la siguiente. La sección 3 presenta la distinción entre interpretación en abstracto e interpretación en concreto en términos básicos, es decir, sin problematizarla y sin tener cuenta de las reformulaciones posteriores. La sección 4 ofrece una reconstrucción del debate que tuvo lugar en la revista Discusiones sobre la distinción objeto del presente análisis meta-teórico, y menciona algunas contribuciones recientes que demuestran la actualidad del tema. La sección 5 toma en cuenta la teoría del significado de Guastini, con una mirada a algunas ideas de Damiano Canale. La sección 6 explica mi propuesta de utilizar el reference-determiner como solución elegante para quedarse con la distinción entre interpretación en abstracto e interpretación en concreto. La sección 7 explica por qué no quiero tomar posición acerca de la prioridad lógica. Finalmente, la sección 8 contiene una pequeña síntesis de mis argumentos. Antes de todo, sin embargo, será útil ofrecer un crash course sobre el núcleo duro del escepticismo interpretativo (sección 2).

1 Comanducci, P., Assaggi di metaetica due, Giappichelli, Torino, 1998, pp. 92-93.

2 Guastini, R., Interpretare e argomentare, Giuffrè, Milano, 2011, pp. 415-18; Diciotti, E., Verità e certezza nell'interpretazione della legge, Giappichelli, Torino, 1999, pp. 81-115. 


\section{Un crash course sobre el escepticismo interpretativo de Guastini}

Siguiendo, con algunas simplificaciones, una reciente reconstrucción propuesta por Nicola Muffato, podemos considerar que el escepticismo jurídico genovés, en general, está caracterizado por algunas tesis fundamentales ${ }^{3}:\left(\mathrm{TH}_{1}\right)$ cualquier enunciado normativo jurídico puede presentar siempre una pluralidad de significados, porque está afectado por ambigüedades y equivocidad ${ }^{4}$; $\left(\mathrm{TH}_{2}\right)$ el intérprete tiene autonomía, discrecionalidad, libertad en elegir uno, o algunos, de estos significados o interpretaciones ${ }^{5}$; $\left(\mathrm{TH}_{3}\right)$ la vaguedad de los predicados presentes en las normas es también fuente de indeterminación lingüística de los enunciados normativos jurídicos y, consecuentemente, de discrecionalidad interpretativa, pero es algo distinto de la equivocidad de los textos normativos ${ }^{6} ;\left(\mathrm{TH}_{4}\right)$ el co-texto en el que se sitúa cada enunciado normativo jurídico, la variedad de construcciones dogmáticas elaboradas por los juristas, y la pluralidad de ideologías ético-políticas subyacentes incrementan exponencialmente indeterminación de cada enunciado normativo jurídico ${ }^{7}$. Estas tesis constituyen el punto de partida del escepticismo de Guastini. Sin embargo, la teoría escéptica de Guastini no puede ser completamente reducida a las cinco asunciones que acabamos de mencionar, ya que contiene un aparato conceptual y definitorio mucho más complejo ${ }^{8}$.

En primer lugar, el escepticismo interpretativo propone un esquema para visualizar la estructura lógica profunda -es decir, aquella ofuscada por la "superficie" sintáctica- de un enunciado interpretativo estándar:

3 Muffato, N., "Sullo scetticismo interpretativo di Riccardo Guastini", en Chiassoni, P., Comanducci, P. y Ratti, G.B. (eds.), L'arte della distinzione. Scritti per Riccardo Guastini. Vol. II, Madrid, Marcial Pons, 2018, pp. 15-51, 17-9.

4 Guastini, R., Interpretare e argomentare, op. cit., pp. 39-70.

5 Idem.

6 Ibidem, pp. 46-56.

Ibidem, pp. 61 y ss.

8 Idem. Véase también Guastini, R., "A Sceptical View on Legal Interpretation", Analisi e diritto, 2005, pp. 139-144; Chiassoni, P., "Lineluttabile scetticismo della 'Scuola genovese”, Analisi e diritto, 1998, pp., 21-76. 
Algunas consideraciones acerca de la distinción entre interpretación en abstracto...

"El enunciado normativo (es decir, la disposición) E significa $S$ " $\left(\mathrm{TH}_{5}\right) 9$. Los enunciados interpretativos carecen de valores de verdad10. Pero este rasgo no implica que los enunciados meta-interpretativos carezcan también de valores de verdad11. Si un enunciado que describe la interpretación (o las interpretaciones) de una disposición corresponde efectivamente a las decisiones interpretativas llevadas a cabo por los jueces dentro del ordenamiento jurídico, el enunciado será verdadero12. En el caso contrario, el enunciado será falso. La verdad se entiende como correspondencia a hechos.

En segundo lugar, Guastini precisa que los enunciados interpretativos tienen una función peculiar: se trata de una adscripción, a su vez entendida como un tertium quid entre aserción y prescripción $\left(\mathrm{TH}_{6}\right)^{13}$. Los enunciados interpretados, entendidos como enunciados en función adscriptiva, por definición, carecen de valores de verdad ${ }^{14}$. Quisiera señalar que alguien podría tener buenas razones para dudar que la adscripción sea una función lingüística diferente -y no reducible a- los conceptos de aserción y prescripción ${ }^{15}$. Todavía, este no es el contexto oportuno para profundizar el tema; entonces, tomaré la noción "guastiniana" de adscripción at face value.

9 Guastini, R. "Interpretive Statements", en Garzón Valdés, E. et al (eds.), Normative Systems in Legal and Moral Theory. Festschrift for Carlos E. Alchourrón and Eugenio Bulygin, Berlin, Duncker \& Humblot, 1997, pp. 279 y ss.; Tarello, G., Diritto, Enunciati, Usi, Bologna, Il Mulino, 1974, pp. 265 ss., 389 ss.

${ }^{10}$ Arena, F., "Distinguir entre teorías de la interpretación y directivas interpretativas", Discusiones, 11, 2012, pp. 13-27, 15.

${ }^{11}$ Alchourrón, C. E., "Logic of Norms and Logic of Normative Propositions", Logique et Analyse, 1969, pp. 242-68; Guastini, R., Le fonti del diritto. Fondamenti teorici, Milano, Giuffrè, 2010, Cap. XXIV.

12 Guastini, R., Interpretare e argomentare, op. cit., p. 216 y ss. Bulygin, E., "El concepto de vigencia en Alf Ross", en C. Alchourrón, E. Bulygin (eds.), Análisis lógico y derecho, Madrid, 1991 , pp. 339 y ss.

${ }^{13}$ Guastini, R., Interpretare e argomentare, op. cit., p. 424; Guastini, R., "El escepticismo ante las reglas replanteado", Discusiones, 11, 2012, pp. 27-57.

${ }^{14}$ La tesis opuesta ha sido defendida recientemente por Ramírez Ludeña, L., "Riccardo Guastini, Las Teorías de la interpretación jurídica y lo verdaderamente correcto", en Chiassoni, P., Comanducci, P. y Ratti, G.B. (eds.), L'arte della distinzione. Scritti per Riccardo Guastini. Vol. II, Madrid, Marcial Pons, 2018, pp. 91-110.

${ }^{15}$ Muffato, N., "Sullo scetticismo interpretativo di Riccardo Guastini", op. cit., pp. 32-4. 
Alessio Sardo

En tercer lugar, Guastini distingue entre interpretación cognitiva, decisoria, y creativa $\left(\mathrm{TH}_{7}\right)^{16}$. Todo texto jurídico es un conjunto de enunciados normativos/disposiciones, que expresa un número finito de normas. Las disposiciones constituyen el objeto de la interpretación, definida como "actividad de atribución de significado (o sentido) a un texto". Las normas constituyen el sentido de los enunciados normativos: ellas corresponden al producto de la interpretación-actividad. Una disposición puede expresar varias normas, pero nunca puede considerarse como una "pantalla en blanco": los significados expresados por una disposición, en un tiempo determinado, están limitados por un marco ${ }^{17}$.

El marco es una metáfora kelseniana que captura los límites de las interpretaciones "razonablemente predecibles" en un cierto tiempo, en función de las técnicas interpretativas, de las tesis dogmáticas, de los usos lingüísticos y valores compartidos por los juristas ${ }^{18}$. La interpretación judicial es siempre una actividad volitiva, o sea, una interpretación decisoria: el juez no identifica el significado "correcto" o "verdadero" de las disposiciones, porque elije siempre, de manera discrecional, uno de los significados que pertenecen al marco, o incluso atribuye a la disposición un significado "nuevo". Los significados del marco son, a lo mejor, más (o menos) persuasivos, pero nunca deben ser considerados como vinculantes o verdaderos ${ }^{19}$. En el caso de creación de un significado por fuera del marco se habla de interpretación creativa.

${ }^{16}$ Guastini, R., Interpretare e argomentare, op. cit., pp. 424 y ss.

17 Ratti, G.B., "Cornici e insiemi” en Chiassoni, P., Comanducci, P. y Ratti, G.B. (eds.), Larte della distinzione. Scritti per Riccardo Guastini. Vol. II, Madrid, Marcial Pons, 2018, pp. 317-25.

${ }^{18}$ Guastini, R., Interpretare e argomentare, op. cit., pp. 59-60 y Guastini, R., "Replica", Rivista di Filosofia del diritto, 2 (1), 2013, p. 131. El marco es ineluctablemente vago. La teoría del marco, así como la tripartición interpretación creativa, decisoria, cognitiva está inspirada por la obra de Kelsen: Kelsen, H., Introduction to the Problems of Legal Theory (1934), trad. de B. Litschevski Paulson y S.L. Paulson, Clarendon Press, Oxford, 1992, p. 80 y s.; Kelsen, H., Pure Theory of Law (1960), trad. de M. Knight, University of California Press, Berkeley-Los Angeles-London, 1967, p. 353 y ss. Véase también Chiassoni, P., Interpretation without Truth, Dordrecht, Springer, 2019, p. 104 y ss.

${ }^{19}$ Sobre este punto, véase también Chiassoni, P., “The Pragmatics of Scepticism”, en Poggi, F. y Capone, A. (eds.), Pragmatics and Law. Practical and Theoretical Perspectives, Berlin, Springer, 2017, pp. 110-2. 
Algunas consideraciones acerca de la distinción entre interpretación en abstracto...

La interpretación cognitiva es el punto de partida de la interpretación-actividad de los jueces y de la dogmática jurídica, pero esto nunca excluye el elemento volitivo de la decisión judicial. Por cierto, la interpretación cognitiva podría ser considerada como la actividad intelectual que una ciencia jurídica digna de tal apellido (es decir, a-valorativa) debería hacer. De todas formas, solo la minoría de los juristas estaría dispuesta a aceptar esta concepción "descriptiva" de la ciencia jurídica ${ }^{20}$.

Finalmente, Guastini pone énfasis en la indeterminación lingüística determinada por la ambigüedad (en sentido amplio), complejidad, o equivocidad de los enunciados normativos jurídicos que, en su opinión, constituye un problema interpretativo "más importante" de la vaguedad $\left(\mathrm{TH}_{8}\right)^{21}$. Las técnicas interpretativas y argumentativas (interpretación literal, sistemática, intención del legislador, etc.) son instrumentos para justificar la adscripción de significado a una disposición, y pueden incrementar o reducir la equivocidad y ambigüedad de cada enunciado normativo jurídico. Entre las varias técnicas interpretativas no hay prioridad lógica o axiológica absoluta $\left(\mathrm{TH}_{9}\right)$.

Por supuesto, Guastini no desconoce la posibilidad de que los juristas argumenten sin recorrer a técnicas interpretativas: pero, en este caso, sería mejor hablar de construcción jurídica, un término que, en la teoría de Guastini, denota cualquier operación lógicamente diferente de la adscripción de significado a una disposición ${ }^{22}$. La construcción jurídica incluye, por ejemplo, la resolución de antinomias, la resolución de (algunos tipos de) lagunas, la institución de jerarquías normativas, la ponderación ${ }^{23}$. La construcción jurídica es una forma de integración del derecho mediante la producción de normas no expresas ${ }^{24}$. Todas estas tesis $\left(\mathrm{TH}_{1}-\mathrm{TH}_{10}\right)$ suelen ser

${ }^{20}$ Guastini, R., Distinguendo ancora, Madrid, Marcial Pons, 2013, p. 116.

${ }^{21}$ Guastini, R., Dalle fonti alle norme, Torino, Giappichelli, 1990, pp. 25- 27; Guastini, R., Interpretare e argomentare, op. cit., pp. 13-33.

${ }^{22}$ Guastini, R., "Interpretación y construcción jurídica", Isonomía 43, 2015, pp. 11-48. Estas definiciones no corresponden a una posible interpretación de la obra de Guastini: más bien, proporcionan relaciones establecidas por Guastini mismo, que parece trazar la distinción entre interpretación y construcción de dos manera distintas.

${ }^{23}$ Guastini, R., "El escepticismo ante las reglas replanteado", op. cit., pp. 27-58, 34.

${ }^{24}$ Guastini, R., Interpretare e argomentare, op. cit., pp. 155-62. 
Alessio Sardo

presentadas por Guastini y sus comentadores como rasgos fundamentales, "conceptuales", quizás necesarios, de los ordenamientos jurídicos occidentales o, al menos, de aquellos que pertenecen a la tradición de civil law ${ }^{25}$.

\section{La distinción en términos básicos}

Ahora bien, establecido este marco conceptual, podemos preguntarnos: ¿cuáles son las tesis de Guastini acerca de la distinción entre interpretación en abstracto e interpretación en concreto? En una primera aproximación, Guastini considera que la interpretación en abstracto es aquella "dirigida a los textos", mientras que la interpretación en concreto es aquella "dirigida a los hechos"26. Además, según Guastini, la primera consiste en identificar el sentido de las disposición, es decir, la(s) norma(s) expresada(s) por una disposición, sin proyectarla sobre el caso individual ${ }^{27}$. La segunda, consiste en subsumir un caso individual en el campo de aplicación de una norma previamente interpretada en abstracto.

Si es así, se trata de dos operaciones lógicamente distintas: la interpretación en abstracto es, propiamente, la atribución de sentido a un texto; la interpretación en concreto, aparentemente, es la inclusión de un conjunto de hechos actuales -o, alternativamente, de una clase de hechos- en una clase -o, alternativamente, en otra clase más general- definida por los predicados factuales de la norma que, normalmente, se encuentran en el antecedente de la misma, y que son asociados a la consecuencia deóntica (asumiendo que las normas son enunciados condicionales). La subsunción es concebida como la actividad de clasificar casos bajo normas. Entonces, si la estructura de la interpretación en abstracto es "El texto T significa S" o "La disposición jurídica D expresa la norma N", la interpretación en concreto corresponde, por ejemplo, a un enunciado como "El hecho F es un caso de $\mathrm{x}^{\prime 28}$.

${ }^{25}$ Muffato, N., "Sullo scetticismo interpretativo di Riccardo Guastini", op. cit., pp. 21-2.

${ }^{26}$ Guastini, R., "El escepticismo ante las reglas replanteado", op. cit., pp. 27-31.

27 Alchourrón, C. E. y Bulygin, E., Normative Systems, Wien/New York: Springer-Verlag, 1971, Cap. I. 
Algunas consideraciones acerca de la distinción entre interpretación en abstracto...

Ahora bien, Guastini concede que interpretación en abstracto e interpretación en concreto, normalmente, son indiscernibles desde un punto de vista psicológico. No obstante, la distinción queda clara en el plan lógico, corroborada por el hecho de que los dos tipos de interpretación resultan ser operaciones intelectuales que manejan objetos diferentes: la interpretación en abstracto "extrae" sentidos "expresados", o "lógicamente implícitos", desde enunciados lingüísticos completos y bien formados, sin hacer referencia al caso concreto; la interpretación en concreto relaciona conjuntos de hechos con predicados que identifican clases ${ }^{29}$.

Si la interpretación en abstracto produce o resuelve problemas de indeterminación del sistema jurídico -eliminando o introduciendo equivocidad e ambigüedad- la interpretación en concreto está relacionada a la indeterminación "interna" de una norma particular -porque se enfrenta a y resuelve problemas de vaguedad de los predicados- $y$, en particular, con respeto a los casos que caen bajo el alcance (en términos de Rudolf Carnap, extensión) de la norma ${ }^{30}$. Si es así, según Guastini, no debería sorprender el hecho que los jueces efectúan regularmente los dos tipos de interpretación, mientras que la doctrina o dogmática jurídica suele llevar a cabo primariamente (o típicamente) interpretaciones en abstracto. Estas consideraciones forman parte de un corolario de las definiciones iniciales que, a su vez, se entienden como equivalentes.

Guastini conecta de manera expresa los dos tipos de interpretación a dos niveles diferentes de significación." 31

Antes de problematizar estas distinciones, será útil introducir unos ejemplos para aclarar el alcance de las mismas. Para evitar cualquier controversia de atribución, voy a retomar unos ejemplos elaborados por Guastini mismo: $:^{32}$

1) El artículo 13 de la Constitución francesa establece: "El Presidente de la Republica firma los decretos y resoluciones emanados del Con-

${ }^{29}$ Guastini, R., "El escepticismo ante las reglas replanteado", op. cit., p. 29.

${ }^{30}$ Guastini, R., Interpretare e argomentare, op. cit., pp. 15-8. Carnap, R., Meaning and Necessity. A Study in Semantics and Modal Logic, Chicago, University of Chicago Press, 1988, p. 23 y ss.

${ }^{31}$ Guastini, R., "El escepticismo ante las reglas replanteado", op. cit., p. 31.

${ }^{32}$ Guastini, R., "El escepticismo ante las reglas replanteado", op. cit., pp. 28-9. 
Alessio Sardo

sejo de Ministros". ¿Esto significa que el Presidente posee el poder de firmar (en el sentido deóntico de permitido) o que tiene el deber (es decir, la obligación) de hacerlo? La interpretación en abstracto ofrece una respuesta a este problema de traducción.

2) El artículo 11 de la Constitución italiana autoriza la República a aceptar "aquellas limitaciones a la soberanía que sean necesarias para el establecimiento de un orden mundial que asegure la paz y la justicia entre Naciones." Ahora bien, un interprete podría preguntarse ¿Cuál es el significado de "soberanía" en este contexto? ¿Se refiere a la independencia del Estado en las relaciones internacionales o al poder político supremo, el pueblo"? La interpretación en abstracto se enfrenta a esto tipos de equivocidad de los enunciados jurídicos.

En cambio, ejemplos paradigmáticos de la interpretación en concreto serían los siguientes:

3) ¿La regla "Prohibido vehículos en el parque" se aplica a las bicicletas o no?

4) ¿La regla constitucional que defiende la libertad de religión se aplica a la religión new-age o no?

Quisiera señalar que la distinción entre interpretación en abstracto e interpretación en concreto estaba, en forma embrionaria, presente en la teoría de Giovanni Tarello. En Diritto, enunciati, usi, Tarello consideraba que muchos enunciados bien formados no expresan una proposición, sino una función proposicional que no puede ser evaluada en abstracto, porque hace falta tomar en cuenta el contexto concreto para obtener lo que Tarello llamaba "enunciado cerrado", es decir, una proposición (normativa o descriptiva) integrada por todos los elementos contextuales ${ }^{33}$. 
Algunas consideraciones acerca de la distinción entre interpretación en abstracto...

\section{El debate entre Guastini y sus críticos}

Como hemos anticipado, la distinción entre interpretación en abstracto e interpretación en concreto fue uno de los temas más discutidos en el animado debate publicado en el numero 11 de Discusiones: ninguno de los críticos de Guastini estaba convencido por esta tipología, que aún hoy es objeto de controversias teóricas.

En su contribución, Isabel Lifante Vidal analiza el problema en el marco de un análisis general que denuncia la tendencia hacia una forma de "segregacionismo discursivo" por parte de Guastini, que, con sus definiciones, se aleja demasiado de las actitudes normativas que constituyen las prácticas lingüísticas de los juristas. Según Lifante Vidal, el derecho incorpora necesariamente una pretensión de corrección (moral) ${ }^{34}$, una mezcla de descripción y evaluación, y la presencia de patrones intersubjetivos de corrección ${ }^{35}$. En particular, Lifante Vidal objetaba que, entre los ejemplos de interpretación en concreto ofrecidos por Guastini, algunos se configuraban como subsunción de un caso genérico (es decir, de una clase de casos) en una norma, y no de subsunción de un caso individual (un conjunto de hechos definido por coordenadas espacio-temporales) dentro de un clase ${ }^{36}$. Esto implica, evidentemente, una ambigüedad de la distinción.

Por ejemplo, decir que "Prohibida la entrada de vehículos en el parque" significa que también la entrada de las bicicletas está prohibida, no parece una interpretación en concreto estrictamente entendida -como parecía sugerir Guastini- precisamente porque corresponde a la inclusión de una clase de entidades, u objetos (las bicicletas), dentro de una clase más amplia (los vehículos). De hecho, si se aplica de manera más estricta la definición de Guastini, para tener una interpretación en concreto hubiera sido necesario reconducir un objeto individual y concreto (la bicicleta del Señor Hugo que, como se dice en filosofía del lenguaje, debe satisfacer

${ }^{34}$ Poggi, F. y Sardo, A., "Do the Right Thing! - Robert Alexy and the Claim to Correctness", Rechtstheorie, 47, 2016, pp. 413-41.

35 Lifante Vidal, I., "Distinciones y paralogismos. A propósito del escepticismo guastiniano", Discusiones, 11, 2012, pp. 59-85, en p. 63 y ss.

${ }^{36}$ Idem. 
el requisito de unicidad $)^{37}$ bajo el ámbito de aplicación de un predicado de la norma ("vehículo", un predicado que se puede atribuir a la bicicleta del Señor Hugo: "La bicicleta del Señor Hugo es un vehículo"). Pero, si se trata de una calificación jurídica que incluye una clase en otra clase, nos quedamos siempre en el nivel abstracto (la subsunción general) y no en el nivel concreto (los casos individuales) ${ }^{38}$.

También Lorena Ramírez Ludeña abordó el problema de la interpretación en abstracto e interpretación en concreto en un ensayo enfocado inter alia sobre la defensa de los valores de verdad de los enunciados interpretativos y la duda acerca del estatuto lógico de las distinciones de Guastini (¿generalizaciones empíricas, tesis conceptuales, proposiciones de una general jurisprudence, o análisis de razonamiento jurídico contingente de los juristas italianos?) $)^{39}$. En primer lugar, Lorena Ramírez intentó mostrar, en oposición a Guastini, que hay casos centrales de aplicación de los predicados de las normas, y casos periféricos. En segundo lugar, sugirió que "los problemas de vaguedad son similares a los que cabría enfrentar cuando se trata de problemas de ambigüedad fruto de la interpretación en abstracto", y "que los problemas propiamente interpretativos que se plantean en la interpretación orientada a hechos son estructuralmente idénticos a los de la interpretación en abstracto" 40 .

La distinción entre interpretación en abstracto e interpretación en concreto tampoco encuentra el favor de Michel Troper que, a diferencia de los otros críticos, notoriamente defiende un escepticismo más radical que el de Guastini ${ }^{41}$. Michel Troper también argumentó que "[S]in embargo,

37 Carnap, R., Meaning and Necessity, op. cit., p. 32: "An (individual) description is an expression of the form ' $(1 \mathrm{x})(. \mathrm{x} .$.$) ' it means 'the one individual such that .. \mathrm{x}$... If there is one and only one individual such that ..x.. we say that the description satisfies the uniqueness condition.".

${ }^{38}$ Ruiz Manero, J., "Epílogo: interpretación jurídica y direcciones de ajuste", Discusiones, 11, 2012, pp. 203-19, MacCormick, N., Legal Reasoning and Legal Theory, Clarendon Press, Oxford, 1978.

39 Ramírez Ludeña, L., "El desvelo de la pesadilla Una respuesta a 'El escepticismo ante las reglas replanteado"', Discusiones, 1, 2012, pp. 87-116.

${ }^{40}$ Ibidem, p. 103.

${ }^{41}$ Troper, M., Pour une théorie juridique de l'Etat, Paris, PUF, 1994. Veàse también Brunet, P., "La théorie réaliste n'est-elle qu'une théorie de l’interprétation?" en J.-J. Sueur (dir.), La 
Algunas consideraciones acerca de la distinción entre interpretación en abstracto...

podemos objetar que las dos operaciones se confunden, y ello no solo, tal como admite el mismo RG [Riccardo Guastini], en el plano psicológico (el orden en el que procedemos es claramente irrelevante), sino más bien en el plano lógico" 42 . Por ejemplo, determinar si la libertad de religión incluye la religión new age no es una operación que se hace mirando a los hechos, sino aclarando el significado del término religión.

En definitiva, según Troper, es todo un problema de interpretación que, conceptualmente, es una actividad en abstracto: "el derecho administrativo francés distingue, tal como lo hace RG [Riccardo Guastini], la interpretación de los textos y la clasificación de los hechos, a la denominada 'calificación jurídica de los hechos', pero se trata simplemente de un intento para disimular el hecho de que también en el segundo caso se interpretan textos" 43 . También un enunciado como "la plaza Beauvau no podría ser considerada en su conjunto como formando parte de una perspectiva monumental", que parecería un ejemplo paradigmático de interpretación en concreto, no hace otra cosa que confeccionar un disfraz para la justificación real del caso: no es un hecho que la plaza Beauvau tiene una "perspectiva monumental", porque esto es más bien una consecuencia del significado de "perspectiva monumental", contenido en el texto de la ley, y aclarado por los jueces ad hoc, caso por caso ${ }^{44}$, de manera casi arbitraria, que encuentra límites puramente políticos ${ }^{45}$.

¿Cuál fue la reacción de Guastini frente a estas objeciones? En primer lugar, quedarse con la distinción entre interpretación en abstracto y en concreto, pero añadiendo una tercera opción "intermedia" -la subsunción genérica- que consiste en la inclusión de una clase de casos adentro de otra clase de casos más amplia. En segundo lugar, sin restringir la definición de interpretación en concreto a la subsunción individual (solución que hubiera sido preferible), concedió que la distinción entre interpretación en abstracto e interpretación en concreto no tiene contornos precisos (está

Transgression, Bruxelles, Larcier, 2013, pp. 397-414.

42 Troper, M., "Anotaciones sobre Guastini”, Discusiones, 11, 2012, pp. 117-33, 119.

43 Ibidem, p. 120.

44 Ibidem, p. 120.

${ }^{45}$ Troper, M., Champeil-Desplats, V. y Grzegorczyk, C., La théorie des contraintes juridiques, Paris, LGDJ, 2005. 
Alessio Sardo

“contagiada" de vaguedad ${ }^{46}$. En tercer lugar, Guastini revisó algunos ejemplos controvertidos, y sugirió que, si se utilizan ejemplos más sofisticados de interpretación en concreto, resulta claro que hay situaciones en que la resolución de un caso requiere mucho más que una subsunción genérica, porque hace falta tomar en cuenta peculiaridades del caso individual para establecer si esto es reconducible a los predicados de la norma interpretada en abstracto ${ }^{47}$. En la réplica, Guastini concedió que, en su planteamiento inicial, había probablemente construido "de manera insatisfactoria" los conceptos de interpretación en abstracto y en concreto, pero que solo "un ciego" no sería capaz de darse cuenta de que hay allí una distinción.

¿Estas réplicas han sido suficientes para resolver la disputa filosófica? La respuesta es negativa. Isabel Lifante Vidal no parece aún convencida por las réplicas de Guastini ${ }^{48}$. También Cristina Redondo y Diego Papayannis han vuelto -nueve años después- a escribir sobre la distinción interpretación en abstracto/interpretación en concreto, defendiendo dos perspectivas opuestas.

Diego Papayannis en un ensayo muy interesante ${ }^{49}$, intenta defender la distinción de Guastini siguiendo una de las líneas argumentativas sugeridas por Guastini en su Replica de 2012: buscar casos más complejos que instancian interpretaciones en concreto. Estoy totalmente de acuerdo con la propuesta de Papayannis de restringir la interpretación en concreto a la así llamada "subsunción individual". Estoy también de acuerdo con la idea de que -como hemos señalado- parte del problema se encuentra en algunos ejemplos que parecen extender la interpretación en concreto también a la inclusión de una clase en otra clase que, justamente, Papayannis

${ }^{46}$ Guastini, R., "Réplica”, op. cit., p. 180 y ss.

47 Ídem.

${ }^{48}$ Vidal Lifante, I., "Distinguiendo Interpretaciones", en Chiassoni, P., Comanducci, P. y Ratti, G.B. (eds.), Larte della distinzione. Scritti per Riccardo Guastini. Vol. II, Madrid, Marcial Pons, 2018, pp. 111-25, 114-5.

49 Papayannis, D., “¡Basta de vehículos en el parque! Una defensa de la distinción entre la interpretación en abstracto y en concreto", Chiassoni, P., Comanducci, P. y Ratti, G.B. (eds.), Larte della distinzione. Scritti per Riccardo Guastini. Vol. II, Madrid, Marcial Pons, 2018, pp. 147-64. 
Algunas consideraciones acerca de la distinción entre interpretación en abstracto...

considera como un asunto diferente: una forma de interpretación extensiva o restrictiva ${ }^{50}$.

Finalmente, los ejemplos ofrecidos por Papayannis son iluminadores: el juez que, en un caso individual, dice que "los muebles de indispensable uso" son aquellos cuya "necesidad' debe ser experimentada por la mayoría de las personas en determinado momento, a que solo están exceptuados del embargo, los bienes corrientes en un hogar de nivel medio de vida" parece sin duda efectuar una interpretación en abstracto. Pero cuando el mismo juez afirma que "el televisor marca Sony 30 pulgares' o "la PlayStation" (no en general, sino aquellos que están allí, pongamos, en el salón del actor) es un "mueble de indispensable uso" está haciendo una interpretación en concreto $^{51}$.

El único elemento que falta a Papayannis es proporcionar definiciones que permitan distinguir analíticamente entre las dos operaciones, desde el punto de vista lógico, para que sus excelentes ejemplos no se queden víctima de la siguiente objeción: ¿Quién dice que cuando el juez habla de la PlayStation o del televisor no está razonando por categorías generales, $\mathrm{o}$ que, si la categorización pertenece a la interpretación en abstracto ${ }^{52}$, todo lo que está en el plano de la interpretación en concreto es trivial? En este ensayo, voy a llevar agua al molino de Papayannis (no con otros ejemplos, sino) introduciendo en el modelo de Guastini un dispositivo semántico apto a mapear la estructura lógica de la interpretación en concreto como algo distinto de la subsunción genérica. Este pasaje toma como punto de partida la teoría del significado defendida por Guastini, añadiéndole un elemento esencial: el reference-determiner.

${ }^{50}$ Velluzzi, V., "La distinzione tra analogia giuridica e interpretazione estensiva", en Manzin, M. y Somaggio, P. (eds.), Interpretazione giuridica e retorica forense. Il problema della vaghezza del linguaggio nella ricerca della verità processuale, Milano, Giuffrè, 2006, pp. 133-48.

${ }^{51}$ Papayannis, D., “ßBasta de vehículos en el parque! Una defensa de la distinción entre la interpretación en abstracto y en concreto", op. cit., p. 153.

52 Sobre la noción de "categorización", véase Schauer, F., Playing by the Rules, Oxford, Claredon Press, 1991, p. 17 y ss. 
Alessio Sardo

\section{La teoría del significado de Guastini}

No cabe duda sobre el hecho de que Guastini tiene -o al menos, presupone- una teoría del significado ${ }^{53}$. Creo que, en esto, Damiano Canale tenía perfectamente razón: una teoría descriptiva de la interpretación (rectius, de las prácticas interpretativas) requiere una teoría del significado previa, aunque esta pueda ser entendida como una tarea metafísicamente "ligera": la mera identificación de los significados con enunciados bien formados, con criterios de traducción, o con reglas de uso que se reflejan en comportamientos lingüísticos, à la Quine o à la Wittgenstein ${ }^{54}$. De todos modos, como dice Canale, la theory of meaning de Guastini ${ }^{55}$, a la hora de proporcionar los criterios de identidad de los enunciados interpretativos, parece comprometerse con una concepción del significado más "exigente" desde el punto de vista metafísico: un modelo de tipo proposicional à la Frege ${ }^{56}$.

La presuposición de una theory of meaning por el escepticismo de Guastini resulta ya clara solo tomando en cuenta la estructura del enunciado interpretativo estándar "El enunciado normativo (la disposición) E significa $S$ ", donde la relación entre los dos enunciados $E$ y $S$ es de significación y, evidentemente, la norma $S$ es el significado de la disposición $E$. El hecho de que el escepticismo de Guastini está vinculado con una específica teoría del significado encuentra un apoyo aún más explícito en las primeras páginas de Interpretare e Argomentare (2011), donde se sitúa el siguiente pasaje que, claramente, se inspira en la obra de Gottlob Frege: "cuando se habla de interpretar un texto, o un discurso, 'interpretar' significa atribuir sig-

${ }^{53}$ Para una reconstrucción de las intricadas relaciones entre interpretación y ontología, véase Hernández Marín, R., "Sobre ontología jurídica e interpretación del derecho", Isonomía, 29, 2008, pp. 33-78.

${ }^{54}$ Quine, V. W. O., “Translation and meaning”, en Id. Word and Object, Cambridge (Mass.), MIT Press, 1960, cap. 2; Quine, V.W.O., "Two Dogmas of Empiricism”, Philosophical Review, 60, 1951, pp. 20-43; Wittgenstein, L., Philosophical Investigations, Oxford, Basil Blackwell, 1953. Barberis, M.,"Lo scetticismo immaginario”, op. cit., pp. 16-7.

${ }_{55}$ Dummett, M., The Seas of Language, Oxford, Oxford University Press, pp. 1-94.

${ }^{56}$ Canale, D., “Teorías de la interpretación jurídica y teorías del significado", Discusiones, 11, 2012, pp. 135-65. Dummett, M., Frege and Other Philosophers, Oxford, Oxford University Press, 1991; Chiassoni, P., "L'ineluttabile scetticismo della 'scuola genovese", op. cit., p. 46 y Luzzati, C., L'interprete e il legislatore, op. cit., p. 146. 
Algunas consideraciones acerca de la distinción entre interpretación en abstracto...

nificado -sentido (Sinn) y referencia (Bedeutung) - a algún fragmento del lenguaje (vocablos, sintagmas, enunciados)" 57 . Obviamente, este pasaje es insuficiente para asumir que Guastini se compromete con toda la teoría de Frege, pero demuestra de manera inequivocable la adhesión a la distinción de matriz fregeana entre sentido y referencia, que presupone la idea más general que los casos, así como cualquier objeto, se representan a través de una descripción de propiedades (los "frásticos" de la norma, diría Guastini $)^{58}$. Como si esto no fuera suficiente, polemizando abiertamente con la obra de Kripke, Guastini precisa que el significado de una disposición existe antes de la interpretación ${ }^{59}$.

Sin alejarse demasiado del pensamiento de Guastini, creo que también se podría añadir a su modelo lo siguiente: tal como los enunciados descriptivos de un lenguaje $L$ son funciones desde objetos a valores de verdad, las disposiciones de un lenguaje normativo $L_{N}$ son (entre otras cosas) funciones desde casos individuales a valores de aplicación (o de satisfacción $)^{60}$. El enunciado descriptivo (E) “ $\xi$ es un vehículo" es una función que proporciona el valor "falso" si el objeto que va a saturar $\xi$ no es un vehículo, y "verdadero" si lo es; análogamente, la disposición (D) “a los $\xi$ que son vehículo está prohibido entrar en el parque" da como resultado "prohibición aplicable" si se trata de vehículo, y "prohibición no aplicable" si no se trata de vehículo.

El Sinn de las normas -entendido como modo de representación de casos- expresa, mediante propiedades generales, las condiciones de aplicación de la norma, es decir: bajo cuales condiciones la consecuencia deóntica se aplica (se encuentra satisfecha por) una clase de casos. El Bedeutung de la norma es el caso individual que, también, contribuye al significado -a la los valores de aplicación- de la disposición, porque, como ya hemos aclarado, la norma asociada a la disposición puede ser aplicable o no aplicable,

57 Frege G. "Über Sinn und Bedeutung", Zeitschrift für Philosophie und philosophische Kritik, 100, 1892, pp. 25-50.

${ }^{58}$ Guastini, R., La sintassi del diritto, Giappichelli, Torino, 2011, p. 29 y ss.; Hare, R.M., Practical Inferences, MacMillan, London, 1971, pp. 89-93.

59 Guastini, R., "El escepticismo ante las reglas replanteado", op. cit., p. 51:

${ }^{60}$ Moreso, J.J., Legal Indeterminacy and Constitutional Interpretation, Dordrecht, Springer, 1998, pp. 7, 12, 24 y ss. 
según el tipo de relación instanciada entre Sinn y Bedeutung, condiciones de aplicación y caso(s) individual(es). Podemos conocer en abstracto las condiciones de aplicación de una norma, es decir, cuáles propiedades un caso debe satisfacer para que la norma se le aplique; pero, no los valores de aplicación de una norma (aplicable/no-aplicable), porque estos se determinan solo a la hora de tomar en cuenta un caso individual, y resolviendo indeterminaciones extensionales (por ejemplo, la vaguedad).

Como esta concepción del significado entendido, à la Frege, como sentido y referencia pueda ser reconciliada con la idea de que "la teoría del significado jurídico no es algo distinto de la teoría de la interpretación jurídica" es otro enigma ${ }^{61}$, que ha sido cuidadosamente analizado en el ensayo de Damiano Canale ${ }^{62}$. Pero nadie podría negar que, en varios pasajes de su copiosa producción, Guastini trabaja con estos dos niveles de significación.

Guastini no dice mucho sobre el sentido de sentido (espero que el lector perdone este juego de palabras), pero queda muy claro que, en su teoría, la palabra "sentido" denota el contenido de las disposiciones -o parte del contenido, asociado a la fuerza ilocucionaria (es decir, lo que se hace diciendo algo: prescribir, sugerir, preguntar, etc. $)^{63}$, que también está semantizado en la norma- y la manera en la que los juristas han solucionado las indeterminaciones del sistema a nivel abstracto.

¿Ahora bien, qué vamos a hacer con todo esto? Hemos visto que el problema principal de la distinción entre interpretación en abstracto y en concreto, es la manera de concebir el producto de la interpretación en concreto: ¿se trata del caso individual como conjunto de hechos particulares - percibidos de manera intuitiva- o, más bien, del "caso individual" como descripción de un estado de cosas mediante propiedades generales, que pueden ir mas allá de un objeto, entidad, acción singular situada en un determinado contexto espacio temporal? Elegir la segunda opción significa que los jueces nunca razonan en términos de caso individual entendido

61 Guastini, R., "El escepticismo ante las reglas replanteado", op. cit., p. 48; Chiassoni, P., Interpretation without Truth, op. cit., p. 84;

${ }^{62}$ Canale, D., "Teoría de la interpretación jurídica y teorías del significado", op. cit.

${ }^{63}$ Sbisà, M., "On Illocutionary Types", Journal of Pragmatics, 8, 1984, pp. 93-112. Austin, J.L., How to Do Things with Words, 2da ed. (Sbisà, M., Urmson, J.U., eds.), Oxford, Oxford University Press, 1975. 
Algunas consideraciones acerca de la distinción entre interpretación en abstracto...

como particular, ya que su pensamiento "funcionaría" siempre (quizás necesariamente) con clases de casos, es decir, casos genéricos.

Pero Guastini había precisado -antes de reformular todo en su réplicaque el producto de la interpretación en concreto es precisamente la referencia de la norma. Si es así, la ambigüedad de la distinción desaparece quedándose solo en los ojos de sus críticos, que se equivocan, concibiendo el producto de la interpretación como un concepto unitario: el significado. Dejando de lado algunos ejemplos infelices de Guastini, queda muy claro que, en su modelo original, la interpretación en concreto, por definición, debe identificar casos individuales, y no es subsunción genérica: basándose en el sistema definitorio de Guastini, la interpretación en concreto de "Prohibido vehículos en el parque" es "Prohibida la bicicleta del Señor Hugo en el parque", y la interpretación en concreto de "Permitido la libertad de religión" es "Permitido profesar Scientology", y no "Permitido profesar religiones new age", porque Scientology es una religión individual, institucionalizada, que tiene coordenadas espacio-temporales precisas (y requisito de unicidad), mientras que las religiones "new age" son, en el mejor de los casos, un subconjunto fuertemente indeterminado de creencias.

Ahora bien, los críticos de Guastini podrían siempre preguntar, de manera no genuina: ¿por qué hace falta distinguir entre sentido y referencia? La necesidad de distinguir entre sentido y referencia ha sido demostrada ampliamente por Gottlob Frege en Über Sinn und Bedeutung $(1892)^{64}$ : el mismo objeto (Venus) puede ser asociado con dos modos diferentes de representación (la estrella matutina y la estrella vespertina), y no siempre los hablantes tienen claro que los diferentes modos de representación se refieren al mismo objeto (Venus). Consideraciones análogas valen para las normas. Además, parece que las competencia lexical involucrada en la determinación del sentido (que se suele llamar "inferencial”) y aquella involucrada en la determinación de la referencia son diferentes ${ }^{65}$ : un juez podría determinar, de manera intuitiva, que los hechos del caso son, pongamos, una instancia de contrato, sin tener clara la teoría de los contratos, $o$ el sentido de las disposiciones que disciplinan el contrato; por el otro lado,

${ }^{64}$ Frege, G., "Über Sinn und Bedeutung", op. cit.

65 Marconi, D., Lexical Competence, Cambridge, MIT Press, 1997. 
un teórico del derecho podría conocer muy bien el sentido (en abstracto) de las disposiciones sobre el contrato y no saber cómo aplicar este conocimiento a un caso individual. Los juristas, como todos los seres humanos, tienen también dos tipos de competencias distintas: inferencial y referencial, que a veces coinciden con la distinción entre know how y know that.

En general, el sentido de una disposición no pertenece a la clase de la así llamadas referring expressions: las normas jurídicas no contienen nombres (Riccardo), descripciones definidas (el hombre más alto del mundo), o términos demostrativos (este hombre, aquel libro) que, si acompañados por un predicado monádico (piensa, por ejemplo) -o por un predicado diádico $y$ otra referring expression (fuma este cigarro)- producen un enunciado completo que determina de manera directa y unívoca su referencia. Por el contrario, las normas jurídicas son normalmente enunciados que contienen, en su estructura semántica, términos generales (los mayores de dieciocho años) y cuantificadores (uno, ninguno, todos, etc.), que no identifican de manera unívoca entidades, objetos, acciones, situaciones individuales.

Por ejemplo, "Prohibido vender pescado en la calle" podría ser una norma jurídica y no se refiere a una entidad o situación particular como los preceptos individuales y concretos "A Pablo está prohibido vender pescado hoy en calle Larios". Los sistemas jurídicos están compuestos por normas como "Prohibido vender pescado en la calle", y no por preceptos individuales y concretos ${ }^{66}$. Por esta razón, no hay un único evento, acción, situación, que puede satisfacer las condiciones de aplicación de la norma (es decir, aplicar la norma), simplemente porque hay potencialmente infinitos eventos acciones, situaciones, que pueden satisfacer (el predicado factual de) una norma. Dicho de manera más técnica, cada norma expresa conceptos que operan como funciones que mapean todos los objetos, acciones, situaciones, entidades que pueden satisfacer sus condiciones de aplicación, definidas por los predicados de la norma: diferentes objetos, acciones, situaciones, entidades pueden instanciar los predicados factuales de una

${ }^{66}$ Laporta, F., El imperio de la ley. Una visión actual, Madrid, Trotta, 2007, en particular p. 86 y ss..; Fuller, L., The Morality of Law, New Haven, Yale University Press, 1969, cap. 2; Guastini, R., Le fonti del diritto e l'interpretazione, Milano, Giuffrè, 1993, p. 22. 
Algunas consideraciones acerca de la distinción entre interpretación en abstracto...

norma. Como vamos a ver en lo que queda de este párrafo y en el siguiente, determinar la referencia de una norma no es una cuestión trivial.

Si la interpretación en concreto de la norma "Prohibido vender pescado en la calle" fuese simplemente "Prohibido vender truchas en la calle", ya que todo se queda en el plan de propiedades generales que denotan casos genéricos, los críticos de Guastini podrían justamente objetar que de genuinamente concreto no hay nada, y que estamos todavía en el plano de la interpretación en abstracto. Pero, si se considera que la interpretación en concreto de la norma "Prohibido vender pescado en la calle" es "Prohibido vender esta trucha [indicando una pez particular] por este hombre [Filippo] en la Calle Larios", o "Prohibido vender la Trucha Willy que pertenece a Filippo" las cosas son diferentes. En este ejemplo el caso es genuinamente individual, y, como dice Guastini, solo un ciego no se daría cuenta de la diferencia.

¿Qué podría decir un crítico acerca de la distinción puesta en estos términos? En primer lugar, que estos enunciados acerca de la Trucha Willy no instancian una forma de interpretación genuina, o que no son relevantes para la teoría de la interpretación. En segundo lugar, que, si es así, la interpretación en concreto no es nada más que la fusión de la premisa menor y de la conclusión normativa del silogismo judicial ((PM) "Prohibido vender pescado en la calle"; (pm) "La Trucha Willy es pescado"; $\therefore$ (CN) "Prohibido vender la Trucha Willy"). Ahora, creo que ninguna de estas objeciones es knock-down. Creo que hay modo de quedarse con la distinción entre interpretación en concreto e interpretación en abstracto si introducimos un ulterior elemento semántico en el escepticismo de Guastini: el reference-determiner, entendido como una función que determina de manera no trivial la relación entre el sentido de una disposición y el caso individual que cae bajo el ámbito de aplicación de la norma, explicitando la relación de cualificación presupuesta en la premisa menor del silogismo judicial. Esta relación es un acto de adscripción mediante una definición estipulativa que se refiere, por definición, a un objeto, entidad, acción, caso, individual. 
Alessio Sardo

\section{El Reference-determiner}

La mejor manera para replantear la interpretación en concreto es definir esta actividad como identificación de la referencia de la norma. Esta es una asunción que permite deshacerse inmediatamente de una ambigüedad inicial, señalada por los críticos: la idea de que la interpretación en concreto puede ser o bien la inclusión de un objeto en una clase, o bien la inclusión de una clase en otra clase. En este replanteamiento, el término interpretación en concreto se refiere solo a la primera operación. La referencia, a su vez, está determinada por una estipulación que establece la referencia a través de un enunciado adscriptivo: el reference-determiner, un tercer nivel de análisis semántico que vamos a añadir al sentido y la referencia. Quisiera subrayar desde el principio que: i) la función del reference-determiner es aclarar la estructura lógica de un enunciado interpretativo en concreto, que nunca ha sido precisada en el debate; ii) esta solución es "elegante" (en sentido técnico) porque el modelo explica el fenómeno de manera clara, directa, y económica. De hecho, la distinción replanteada utiliza un elemento semántico adicional, muy simple, para dar cuenta de la noción de interpretación en concreto. Además, el reference-determiner no requiere revisar ninguna de las tesis que forman parte de la teoría de Guastini y, sobre, todo no requiere abandonar la idea de que los enunciados interpretativos son adscriptivos.

Es muy raro que la referencia de una norma sea el resultado de una derivación lógica. Por el contrario, casi siempre la referencia es determinada por una estipulación que tiene la siguiente forma lógica:

(1) “(x) (El predicado 'a’ SE REFIERE A x sii x es $\varphi$ )” [sii = si y solo si]

Así como podemos establecer la referencia del nombre Riccardo con una estipulación que tiene la siguiente forma lógica:

(2) “(x) ('Riccardo' SE REFIERE A x sii [Riccardo] ( $\mathrm{x}=$ ha sido bautizado Riccardo))" 
Algunas consideraciones acerca de la distinción entre interpretación en abstracto...

Podemos establecer que la referencia del predicado "pescado" es determinada por una estipulación que tiene la misma forma lógica:

(3) “(x) (El predicado 'Pescado' SE REFIERE A Trucha Willy sii [Trucha Willy] (Trucha Willy es trucha))".

Yo aquí utilizo "SE REFIERE A" en reemplazo del símbolo “ $\downarrow \downarrow$ ” utilizado por Gillian Russell de la siguiente manera: “ $\downarrow$ Pescado $\downarrow$ ”. Si queremos traducir estos tipos de estipulación usando la formalización más común, proporcionada por Bertrand Russell y Alfred N. Whitehead en Principia Mathematica $(1903)^{67}$, podríamos escribir el enunciado "El $\varphi$ es F" con la siguiente forma lógica:

(4) $(\exists \mathrm{x})((\phi \mathrm{x} \&(\forall \mathrm{y})(\phi y \rightarrow y=x) \& F \mathrm{x})$.

Que se lee así: "Hay un $x$ tal que $x$ es un $\varphi$, no hay un $y$, distinto de $\mathrm{x}$, tal que $y$ es $\varphi$, e $y x$ es $F$." La proposición (3) difiere de la (4) porque, mientras que (4) parece comprometerse con un uso atributivo (hay un único $x$ tal que $x$ es etc. etc.), la proposición (3) pone el énfasis en el uso referencial, es decir, refiere la propiedad directamente al individuo sin atribución previa ${ }^{68}$. No obstante, en ningún caso estamos utilizando clases de casos. Este pasaje determina la conjunción entre la interpretación en abstracto - una función desde disposiciones a sentido(s) - y la referencia (el caso individual). De este modo, se define la interpretación en concreto como estipulación que determina la relación entre un objeto del caso individual y un predicado de la norma. El pasaje se encuentra implícito en la premisa menor del silogismo judicial, y es necesario para determinar el significado de la disposición -los valores de aplicación- con referencia al caso concreto: el sentido de la disposición expresa las condiciones de aplicación; el reference-determiner expresa las condiciones de introducción de un predicado, de un

67 Whitehead, A.N. y Russell, B., Principia Mathematica, Cambridge, Cambridge University Press, 1962; Russell, B., “On Denoting”, Mind, 1905, 14 (4), pp. 479-493.

${ }^{68}$ Devitt, M., "The Case for Referential Descriptions”, en Bezuidenhout, M. y Reimer, M., Descriptions and Beyond, Oxford, Clarendon Press, 2004, pp. 280-305; Bach, K., "Referentially Used Descriptions: A Reply to Devitt”, European Journal of Analytic Philosophy, 2007, 3(2), pp. 33-48. 
término, de las normas, en una circunstancia particular, que corresponde a lo que G.H. von Wright llamaba "ocasión de las normas"69.

Claramente, para dar cuenta de esto, hace falta añadir un tercer nivel semántico en el análisis de Guastini, fundado en los dos conceptos de sentido y referencia: el reference-determiner. El reference-determiner identifica la condición que un objeto, entidad, acción individual debe satisfacer para caer en la extensión/ser la referencia de una expresión ${ }^{70}$. De acuerdo con las premisas escépticas del modelo de Guastini, podemos asumir que el reference-determiner es sensible con respeto al contexto del caso, y puede variar de intérprete a intérprete ${ }^{71}$, precisamente porque es una estipulación que explicita la condición bajo la cual se introduce el término; en el razonamiento jurídico, esta estipulación (que captura el contexto de introducción) se hace normalmente a la hora de decidir un caso (entonces, el contexto de introducción coincide con el contexto de evaluación del caso).

$\mathrm{Si}$, por un lado, la interpretación en abstracto produce como resultado el sentido que el intérprete competente atribuye a una disposición, utilizando las técnicas interpretativas, por el otro lado, el reference-determiner fija la condición, $\mathrm{o}$ las condiciones, que determina(n) la referencia $\mathrm{o}^{72}$, en otras palabras, formula la definición que estipula cuáles son las condiciones que un objeto individual debe satisfacer para caer bajo la extensión de una expresión ${ }^{73}$.

$\mathrm{Si}$, en el lenguaje ordinario, la determinación de la referencia está hecha con la intención de referirse siempre a un cierto objeto (estipulamos que "Agua $=\mathrm{H}_{2} \mathrm{O}$ " para todos, no solo para los genoveses), en el derecho la determinación de la referencia es relativa a la decisión individual del juez, limitadamente al caso, que coincide con el contexto de introducción (según el juez A, relativamente al caso $x$, aplicando la técnica interpretativa $f_{y}$ "pescado" se refiere a Trucha Willy) ${ }^{74}$. El resultado de una interpretación en

69 Von Wright, G.H., Norm and Action. A Logical Enquiry, London, Routledge \& Kegan Paul, 1963, p. 79.

${ }^{70}$ Russell, G., Truth in Virtue of Meaning: A Defence of the Analytic/Syntetic Distinction, Oxford, Oxford University Press, 2008, x, 46.

${ }^{71}$ Ibidem, p. 47.

${ }^{72}$ Ibidem, p. 47, nota 2.

${ }^{73}$ Ibidem, p. 97.

${ }^{74}$ Ibidem, p. 54. 
Algunas consideraciones acerca de la distinción entre interpretación en abstracto...

concreto es entonces una función que, a partir del sentido (determinado por el contexto en el que ha sido formulada la disposición y de las técnicas interpretativas), y del contexto introducción (el caso individual), da como resultado la referencia. Los valores de aplicación no son necesariamente relativos al contexto de evaluación (el caso concreto), pero, como se dijo antes, hay generalmente una coincidencia temporal del los dos contextos de introducción y de evaluación, que determina un overlap de los dos.

El reference-determiner, básicamente, establece que un objeto $x$ es una instancia del predicado $\varphi^{75}$. Como explica Gillian Russell, por un lado, esta perspectiva es diferente de la visión de los fregeanos clásicos, que consideran la referencia como algo determinado por el contenido descriptivo del sentido; por el otro, difiere también de la perspectiva que la referencia está determinada por hechos independiente de los hablantes (en nuestro caso, de los intérpretes). El reference-determiner está vinculado a situaciones, objetos, entidades, acciones, concretas, y no a clases de objetos ${ }^{76}$.

En síntesis: el reference-determiner es un dispositivo condicional que muestra la definición implícita que ha sido utilizada (en la formulación de la premisa menor) para identificar el referente, y no el sinónimo de la disposición ${ }^{77}$. Depende del contexto de introducción y no determina de manera completa el significado de la disposición ${ }^{78}$.

Sin embargo, algunas veces, lo que Guastini llama interpretación en concreto parece, efectivamente, manejar clases de casos, y no casos individuales. Tomamos por ejemplo el caso de Radio Vaticana ${ }^{79}$, propuesto por Federico Arena como ejemplo de interpretación en concreto según la teoría de Guastini ${ }^{80}$. En este caso, la Corte de Casación Italiana debía establecer si las ondas electromagnéticas emitidas por las antenas de Radio Vaticana, que habían causado daños a los vecinos de la zona, entraban o no en la prohibición de arrojar cosas peligrosas establecida por el artículo 674 del Código Penal. La Corte consideró que en el significado de la expresión "arrojar cosas peli-

${ }^{75}$ Ibidem, p. 65.

76 Ibidem, p. 98.

${ }^{77}$ Ibidem, p. 158

${ }^{78}$ Ibidem, p. 184

${ }^{79}$ Cassazione penale sez. III, 13/05/2008, n. 36845.

${ }^{80}$ Arena, F., "Distinguir entre teorías de la interpretación y directivas interpretativas", op. cit., p. 17. 
grosas", entraban también la creación, la emisión y la propagación de ondas electromagnéticas. Creo que hay dos maneras para resolver este problema.

Una primera manera, muy sencilla, es decir que en este caso -y en otras situaciones similares- cuando los jueces se refieren a las "ondas electromagnéticas", están utilizando claramente una forma elíptica para referirse a las 'ondas electromagnéticas emitidas por Radio Vaticana' y, entonces, no a una clase general, sino a un particular. Pero no siempre es así: a veces, los jueces solucionan mencionando principalmente propiedades generales. Aquí entra la segunda solución, que se aplica a las sentencias donde la determinación de la referencia para el caso particular no es explícita: podemos considerar que, si bien no está completamente explicitada, la interpretación en concreto es el último pasaje que queda implícito en la argumentación de los jueces. Claramente, para decidir el caso, deben haber utilizado algo como el operador "SE REFIERE A", porque, sin este pasaje, no se puede "cerrar" el silogismo judicial bajo consecuencia lógica. Si hay ambigüedad en la motivación, es un problema de la manera en que argumentan los jueces, y no de la teoría de Guastini (en la versión aquí propuesta), siempre que no sea ambiguo el meta-lenguaje también, dejando espacio en el esquema del reference-determiner para un cuantificador universal (todos los $\mathrm{x}$ son $\varphi \mathrm{o}$ ningún $\mathrm{x}$ es $\varphi$ ), o para otros dispositivos que universalizan la operación llevada a cabo por el reference-determiner. Para evitar consecuencias negativas en el meta-lenguaje, se puede introducir ulteriores elementos formales en la estructura del reference-determiner:

$$
\left(2^{*}\right) \text { “ }(\exists x)\left(\text { El predicado ‘a' SE REFIERE } \mathrm{w}_{\mathrm{t}, \mathrm{p}} \text { a x sii x es } \varphi\right) \text { ” }
$$

Donde hay un cuantificador existencial ( $\exists x$, "existe un/una $x$ ") en lugar de un cuantificador universal ( $\forall$, "cualquier $x$ ", que denota una pluralidad de objetos), y el operador "SE REFIERE” está indexado a un mundo (w), tiempo $(\mathrm{t})$, y espacio (p) que mira a buscar, mapear, rasgos del caso individual. De esta manera, podemos reformular en forma extendida (ES) el enunciado $2^{\star}$ en el modo siguiente:

$\left(2_{E S}^{*}\right)$ “( $\left.\exists \mathrm{x}\right)$ ('Pescado') SE REFIERE w,t,p, a Trucha Willy sii [Trucha Willy] (Trucha Willy es trucha))". 
Algunas consideraciones acerca de la distinción entre interpretación en abstracto...

De esta manera podemos explicitar que solo hay un $x$, por lo que el término "Pescado" se refiere a Trucha Willy si y solo si Trucha Willy es, nótese bien, una trucha, no "si es pescado"), donde "se refiere" es relativo a un mundo, tiempo y espacio que identifica el caso individual. En la fórmula la relación de referencia no es absoluta. El reference-determiner vincula a un tipo de actitud de re respeto al caso individual ${ }^{81}$. Las actitudes de re están dirigidas a relaciones contextuales y no puramente conceptuales con los hechos del caso (memoria, creencias introspectivas, presagios acerca del futuro, etc.). Por el contrario, las actitudes de dicto son fundamentales en las inferencias que operan a nivel de sentidos, se encuentran mediadas por una representación conceptual de los hechos del caso mediante propiedades generales.

Me parece que lo que hemos dicho hasta ahora aclara dos funciones primarias que justifican la introducción del reference-determiner. En primer lugar, es un elemento semántico elegante (en el sentido técnico ya aclarado) que demuestra como la identificación de la referencia no es un asunto trivial. En segundo lugar, considerado que el reference-determiner es una forma de estipulación que tiene una función adscriptiva, hemos justificado también la posibilidad de decir que la interpretación en concreto es interpretación, sin alterar dos axiomas de la teoría de Guastini: la idea de que la interpretación jurídica funciona como una definición, y la idea de que es un acto adscriptivo. En tercer lugar, el reference-determiner permite mantener la separación entre interpretación en abstracto e interpretación en concreto. La interpretación en abstracto, normalmente, resuelve tipos de indeterminaciones semánticas y pragmáticas diferentes a la mera identificación de los objetos que caen en la extensión de un predicado, formas de indeterminación a las que Guastini se refiere alternativamente con los términos "ambigüedad", "equivocidad" y "complejidad" 82 . Voy a detenerme un poco sobre este último punto para mostrar la utilidad del reference-determiner en la distinción entre interpretación en abstracto e interpretación en concreto.

Como hemos aclarado, la interpretación en abstracto concierne la posibilidad que una disposición D exprese las normas N1 y/o N2, o que la

${ }^{81}$ Burge, T., "Belief De re", Journal of Philosophy, 74(6), 1977, pp. 338-62.

${ }^{82}$ Guastini, R., “El escepticismo ante las reglas replanteado”, op. cit., p. 40. 
norma expresada por N1 implique también la norma N2. Un ejemplo de interpretación en abstracto es la disposición que establece que el referéndum derogatorio no es admisible "en el año anterior al fin del ejercicio legislativo de una de las dos Cámaras”. Ahora bien, ¿Qué significa "año" en este contexto? ¿Significa 365 días, o significa el periodo que va desde el $1^{\circ}$ de enero al 31 de diciembre? Este es un problema de interpretación en abstracto, y, claramente, no puede ser resuelto por el reference-determiner que, quizás, podrá establecer si el 2018 o el 2019 cae bajo la extensión del predicado "año" en uno de sus dos sentidos, o que el Referéndum propuesto por los simpatizantes del Movimento Cinque Stelle sobre el asunto $x$ cuenta como Referéndum. La distinción, me parece, es bastante clara.

Pero deberíamos conceder que, en razón de la gran variedad de razonamientos que quedan capturados dentro de la interpretación en abstracto -debido al concepto omnicomprensivo de equivocidad (o complejidad, o ambigüedad en sentido amplio) proporcionado por Guastini- haría falta precisar la estructura lógica de cada uno de estos razonamientos, y mostrar que son todos diferentes de una mera determinación de la referencia.

De hecho, la interpretación en abstracto de Guastini comprende la solución de los siguientes tipos de "equivocidad" del lenguaje normativo, que forman una lista no exhaustiva ${ }^{83}$ : i) disposiciones cuya fuerza ilocucionaria no está bien determinada, como el Artículo 13 de la Constitución Francesa sobre la obligación de firma del presidente (¿Es un permiso, una obligación, un poder?); ii) situaciones en que no podemos entender bien las implicaturas (por ejemplo no sabemos si la conjunción "y" en la disposición D expresa también una sucesión temporal entre los elementos conjuntos: 2 "hacer $x \mathrm{e}$ $y$ " significa también "hacer $x$ y después hacer $y$ "? $)^{84}$; iii) contextos donde el dominio del discurso está indeterminado (¿" “prohibido jugar al balón en la calle" tiene como dominio todos los juegos de balón, o solo a fútbol?) ${ }^{85}$; iv) el problema que en filosofía del lenguaje se llama conditional perfection ("A quien no colabora con la policía, se le impondrá una sanción de 500 Euros",

\footnotetext{
83 Chiassoni, P., Interpretation without Truth, op. cit., p. 95 y ss.

${ }^{84}$ Marmor, A., Philosophy of Law, Princeton \& Oxford, Princeton University Press, 2010, pp. 152-8.

85 Gauker, C., "Domain of Discourse”, Mind, 106, 1997, pp. 1-32.
} 
Algunas consideraciones acerca de la distinción entre interpretación en abstracto...

¿es un condicional o un bicondicional?) ${ }^{86}$; iv) indeterminaciones que necesitan formas de contextual enrichment, como el broadening o narrowing (Por ejemplo: "Prohibido fumar" ¿Cigarrillos, pipas o qué más?) ${ }^{87}$. Representar la estructura semántica de todos estos enunciados es un proyecto muy complejo y largo, que va mucho más allá de las ambiciones sin duda más modestas del presente balance.

\section{Algunas consideraciones acerca de la prioridad lógica}

Riccardo Guastini aclara que la distinción entre interpretación en abstracto e interpretación en concreto es "lógica"; pero, de hecho, las prácticas de los juristas (el lenguaje objeto) parecen funcionar de la manera opuesta: si alguien se pone a leer una sentencia cualquiera de cualquier tribunal (Corte constitucional, Corte de Casación, Tribunal Administrativo Regional), se da cuenta que los jueces suelen empezar por la reconstrucción de los hechos del caso, parcialmente calificado jurídicamente, de manera quizás intuitiva, $y$, solo después de este pasaje previo, aplican las técnicas interpretativas y argumentativas a las disposiciones relevantes. Si es así, sería razonable asumir que las inferencias que permiten calificar jurídicamente un conjunto de hechos relevantes no solo determinan la manera de reconducir los hechos a una norma previamente interpretada en abstracto, sino que contribuyen -o al menos influyen de una manera no trivial- en los procesos de desambiguación y determinación del marco de la disposición (interpretación en abstracto).

Cabe subrayar que la tesis según la cual interpretación en abstracto e interpretación en concreto no son lógicamente independientes, acompañada por la idea de que no hay prioridad lógica de la primera sobre la segunda, es un elemento de desacuerdo entre el escepticismo interpretativo de Riccardo Guastini y otras formas de escepticismo interpretativo

${ }^{86}$ Horn, L.R., "From If to Iff: Conditional Perfection as Pragmatic Strengthening", Journal of Pragmatics, 32(3), 2000, pp. 289-326.

87 Carston, R., "Enrichment and Loosening: Complementary Processes in Deriving the Proposition Expressed?", Pragmatik, 8, 1997, pp. 103-27; Villa, V., Una teoria pragmaticamente orientate dell'interpretazione giuridica, Giappichelli, Torino, 2012, p. 117 y ss. 
Alessio Sardo

(siempre de matriz genovés) como, por ejemplo, aquella defendida por Mauro Barberis y Nicola Muffato. Mauro Barberis ha expresado la relevancia del caso concreto en la determinación del sentido de una disposición en varios trabajos ${ }^{88}$. La oposición entre Guastini, por un lado, y Barberis y Muffato, por el otro, no es simplemente técnica, puesto que refleja un desacuerdo sustancial sobre la semántica y pragmática de la interpretación. Un modelo de interpretación enfocado en el papel que el caso concreto juega en la determinación del significado implica un "contextualismo" y "situacionismo" más radical del contextualismo moderado de Guastini ${ }^{89}$.

El contextualismo requiere revisar algunas asunciones del modelo de Guastini, in primis la forma del enunciado interpretativo simple, que deberá incorporar una referencia al contexto. El esquema de Guastini "El enunciado normativo (la disposición) E significa S" deberá ser sustituido por el enunciado "Si elige la directiva hermenéutica x (y/o la definición y/o la tesis dogmática z) para interpretar $\mathrm{E}$ (en el contexto C), entonces $\mathrm{E}$ significa S (in C)"90, porque cada acto interpretativo determina el sentido de un enunciado no en abstracto -como en el modelo de Guastini- sino relativamente al contexto situacional, que incluye elementos del caso concreto $^{91}$. Además, el modelo de Barberis se compromete con un naturalismo filosófico en el análisis del lenguaje ${ }^{92}$, donde los primitivos conceptuales no son entidades abstractas como disposiciones, contenidos de sentidos o proposiciones normativas, sino elementos particulares como individuos, propiedades, relaciones, eventos y coordenadas espacio-temporales.

${ }^{88}$ Barberis, M., Il diritto come comportamento, Torino, Giappichelli, 1988, p. 50 y ss.; Barberis, M., "Lo scetticismo immaginario", op. cit.; Barberis, M., Una filosofía del diritto per lo stato costituzionale, Torino, Giappichelli, 2017, p. 177 y ss.

${ }^{89}$ Barwise, J. y Perry, J., Situations and Attitudes, Cambridge, Mass., The MIT Press, 1983; Barwise, J. y Perry, J., "Shifting Situations and Shaken Attitudes", Linguistics and Philosophy, 8, 1985, pp. 103-161.

90 Muffato, N., "Sullo scetticismo interpretativo di Riccardo Guastini”, op. cit., p. 39.

${ }_{91}$ Muffato, N., "Sullo scetticismo interpretativo di Riccardo Guastini", op. cit., p. 47.

92 Barberis, M., L'evoluzione nel diritto, Giappichelli, Torino, 1997. La naturalización del derecho es un rasgo característico de las teorías realistas: sobre la relación entre naturalización del derecho y realismo, véase Leiter, B., Naturalizing Jurisprudence, Oxford, Oxford University Press, 2007. 
Algunas consideraciones acerca de la distinción entre interpretación en abstracto...

Una forma de contextualismo intermedia, respeto al contextualismo moderado de Guastini y al contextualismo más radical de Barberis y Muffato, es aquella defendida por Pierluigi Chiassoni. Chiassoni, como Barberis y Muffato, considera la interpretación como un juego lingüístico contextual ${ }^{93}$, pero intenta reducir los diferentes juegos interpretativos a esquemas de traducción que mapean la estructura lógica profunda de los códigos interpretativos ${ }^{94}$. Según Chiassoni, los códigos interpretativos son solo parcialmente independientes de los elementos contextuales y situacionales del caso. Los códigos interpretativos son conjuntos de reglas que determinan el producto de la interpretación de manera reflexiva, respeto a los elementos situacionales y contextuales del caso concreto. En el modelo de Chiassoni, los efectos del caso concreto sobre la interpretación en abstractos son mitigados, porqué el contexto del caso llega por el filtro computacional de las reglas que definen la actividad interpretativa.

Las diferencias entre el modelo de Chiassoni, por un lado, y el modelo de Barberis y Muffato, por el otro, no deben ser exageradas. Todos estos autores comparten una postura contextualista y la idea wittgensteiniana de juego interpretativo ${ }^{95}$; mas, mientras Chiassoni cree en la posibilidad de elaborar códigos interpretativos (elegidos por los intérpretes de manera discrecional $)^{96}$, Barberis y Muffato consideran que los juegos interpretativos escapan a un ejercicio de codificación. De todos modos, Chiassoni también reconoce el papel del caso concreto, pero quizás -al menos hasta ahora- no parece dispuesto a una inversión del orden de prioridad en el plano lógico ${ }^{97}$.

${ }^{93}$ Chiassoni, P., Interpretation without Truth, op. cit., p. 86 y ss.

${ }^{94}$ Chiassoni, P., El problema del significado juridico, CDMX (México), Fontamara, 2019, p. 112 y ss.

${ }^{95}$ Chiassoni, P., "Interpretive Games Revisited", en Chiassoni, P., Comanducci, P. y Ratti, G.B. (eds.), Larte della distinzione. Scritti per Riccardo Guastini. Vol. II, Madrid, Marcial Pons, 2018, pp. 165-96, en particular p. 177 y ss. Chiassoni, P., Interpretation without Truth, op. cit., p. 1 y ss.

96 Chiassoni, P., Interpretation without Truth, op. cit., p. 109; Chiassoni, P., "Interpretive Games: Statutory Construction Through Gricean Eyes", Analisi e diritto, 1999, p. 86 y ss.

${ }_{97}$ Chiassoni, P., Interpretation without Truth, op. cit., pp. 80-1 y, sobre todo, pp. 126-7, nota 3. 


\section{Conclusión}

En el presente ensayo he intentado delinear un balance del debate sobre la teoría escéptica de Riccardo Guastini, que tuvo lugar en el numero 11 de la revista Discusiones. Espero que este balance contribuya a la defensa de la tesis, señalada también por Barberis, Canale, Chiassoni y Muffato, según la cual las teorías del significado pueden y deben jugar un papel central en una teoría de la interpretación. El presente análisis se ocupa, desde una perspectiva semántica, de un punto específico del debate, que sigue siendo un enigma filosófico: la distinción entre interpretación en abstracto e interpretación en concreto. Después de haber presentado los argumentos contra la distinción, he elaborado una posible línea de defensa, fundada en la introducción del reference-determiner, como instrumento para explicitar la operación de adscripción implícita en la estipulación que determina la referencia (Bedeutung) de una norma frente a un caso concreto. De este modo, sería posible quedarse con la distinción entre la indeterminación del sistema y los problemas de indeterminación extensional de las normas como entidades singulares.

\section{Bibliografía}

Alchourrón, C. E., "Logic of Norms and Logic of Normative Propositions", Logique et Analyse, 1969, pp. 242-68.

Alchourrón, C. E., Bulygin, E., Normative Systems, Wien/New York: Springer-Verlag, 1971.

Arena, F., "Distinguir entre teorías de la interpretación y directivas interpretativas", Discusiones, 11, 2012, pp. 13-27.

Austin, J.L., How to Do Things with Words, 2da ed, (Sbisà, M., Urmson, J.U., eds.), Oxford, Oxford University Press, 1975.

Bach, K., "Referentially Used Descriptions: A Reply to Devitt", European Journal of Analytic Philosophy, 2007, 3(2), pp. 33-48.

Barberis, M., Il diritto come comportamento, Torino, Giappichelli, 1988.

Barberis, M., L'evoluzione nel diritto, Giappichelli, Torino, 1997. 
Algunas consideraciones acerca de la distinción entre interpretación en abstracto...

Barberis, M., Una filosofia del diritto per lo stato costituzionale, Torino, Giappichelli, 2017.

Barwise, J. y Perry, J., "Shifting Situations and Shaken Attitudes", Linguistics and Philosophy, 8, 1985, pp. 103-161.

Barwise, J. y Perry, J., Situations and Attitudes, Cambridge, Mass., The MIT Press, 1983.

Brunet, P., "La théorie réaliste n’est-elle qu'une théorie de l'interprétation?" en J.-J. Sueur (dir.), La Transgression, Bruxelles, Larcier, 2013, pp. 397414.

Bulygin, E., "El concepto de vigencia en Alf Ross", en C. Alchourrón, E. Bulygin (eds.) Análisis lógico y derecho, Madrid, 1991.

Burge, T., "Belief De re", Journal of Philosophy, 74 (6), 1977, pp. 338-62.

Canale, D., "Teorías de la interpretación jurídica y teorías del significado", Discusiones, 11, 2012, pp. 135-65.

Carnap, R., Meaning and Necessity. A Study in Semantics and Modal Logic, Chicago, University of Chicago Press, 1988.

Carston, R., "Enrichment and Loosening: Complementary Processes in Deriving the Proposition Expressed?", Pragmatik, 8, 1997, pp. 103-27. Chiassoni, P., "Interpretive Games Revisited", en Chiassoni, P., Comanducci, P. y Ratti, G.B. (eds.), Larte della distinzione. Scritti per Riccardo Guastini. Vol. II, Madrid, Marcial Pons, 2018.

Chiassoni, P., "Interpretive Games: Statutory Construction Through Gricean Eyes", Analisi e diritto, 1999.

Chiassoni, P., "Lineluttabile scetticismo della 'Scuola genovese"', Analisi e diritto, 1998, pp. 21-76.

Chiassoni, P., “The Pragmatics of Scepticism”, en Poggi, F. y Capone, A. (eds.), Pragmatics and Law. Practical and Theoretical Perspectives, Berlin, Springer, 2017.

Chiassoni, P., El problema del significado jurídico, CDMX (México), Fontamara, 2019.

Chiassoni, P., Interpretation without Truth, Dordrecht, Springer, 2019.

Comanducci, P., Assaggi di metaetica due, Giappichelli, Torino, 1998. 
Alessio Sardo

Devitt, M., “The Case for Referential Descriptions", en Bezuidenhout, M. y Reimer, M., Descriptions and Beyond, Oxford, Clarendon Press, 2004, pp. 280-305.

Diciotti, E., Verità e certezza nell'interpretazione della legge, Giappichelli, Torino, 1999.

Dummett, M., Frege and Other Philosophers, Oxford, Oxford University Press, 1991.

Dummett, M., The Seas of Language, Oxford, Oxford University Press, 1993.

Frege G., "Über Sinn und Bedeutung", Zeitschrift für Philosophie und philosophische Kritik, 100, 1892.

Fuller, L., The Morality of Law, New Haven, Yale University Press, 1969.

Gauker, C., "Domain of Discourse", Mind, 106, 1997, pp. 1-32.

Guastini, R., Dalle fonti alle norme, Torino, Giappichelli, 1990.

Guastini, R., Distinguendo ancora, Madrid, Marcial Pons, 2013.

Guastini, R., "A Sceptical View on Legal Interpretation", Analisi e diritto, 2005, pp. 139-144.

Guastini, R., "El escepticismo ante las reglas replanteado", Discusiones, 11, 2012, pp. 27-57.

Guastini, R., "Interpretive Statements", en Garzón Valdés, E. et al (eds.), Normative Systems in Legal and Moral Theory. Festschrift for Carlos E. Alchourrón and Eugenio Bulygin, Berlin, Duncker \& Humblot, 1997, pp. 279 y ss.

Guastini, R., "Replica", Rivista di Filosofia del diritto, 2 (1), 2013.

Guastini, R., Interpretare e argomentare, Giuffrè, Milano, 2011, pp. 415-18.

Guastini, R., La sintassi del diritto, Giappichelli, Torino, 2011.

Guastini, R., Le fonti del diritto e l'interpretazione, Milano, Giuffrè, 1993.

Guastini, R., Le fonti del diritto. Fondamenti teorici, Milano, Giuffrè, 2010.

Hare, R.M., Practical Inferences, MacMillan, London, 1971.

Hernández Marín, R., "Sobre ontología jurídica e interpretación del derecho", Isonomía, 29, 2008, pp. 33-78.

Horn, L.R., "From If to Iff: Conditional Perfection as Pragmatic Strengthening", Journal of Pragmatics, 32 (3), 2000, pp. 289-326. 
Algunas consideraciones acerca de la distinción entre interpretación en abstracto...

Kelsen, H., Introduction to the Problems of Legal Theory (1934), trad. de B. Litschevski Paulson y S.L. Paulson, Clarendon Press, Oxford, 1992. Kelsen, H., Pure Theory of Law (1960), trad. de M. Knight, University of California Press, Berkeley-Los Angeles-London, 1967.

Laporta, F., El imperio de la ley. Una visión actual, Madrid, Trotta, 2007.

Leiter, B., Naturalizing Jurisprudence, Oxford, Oxford University Press, 2007.

Lifante Vidal, I., "Distinciones y paralogismos. A propósito del escepticismo guastiniano", Discusiones, 11, 2012, pp. 59-85.

Lifante Vidal, I., "Distinguiendo Interpretaciones", en Chiassoni, P., Comanducci, P. y Ratti, G.B. (eds.), L’arte della distinzione. Scritti per Riccardo Guastini. Vol. II, Madrid, Marcial Pons, 2018, pp. 111-25.

MacCormick, N., Legal Reasoning and Legal Theory, Clarendon Press, Oxford, 1978.

Marconi, D., Lexical Competence, Cambridge, MIT Press, 1997.

Marmor, A., Philosophy of Law, Princeton \& Oxford, Princeton University Press, 2010.

Moreso, J.J., Legal Indeterminacy and Constitutional Interpretation, Dordrecht, Springer, 1998.

Muffato, N., "Sullo scetticismo interpretativo di Riccardo Guastini" en Chiassoni, P., Comanducci, P. y Ratti, G.B. (eds.), L’arte della distinzione. Scritti per Riccardo Guastini. Vol. II, Madrid, Marcial Pons, 2018, pp. 15-51.

Papayannis, D., “ßBasta de vehículos en el parque! Una defensa de la distinción entre la interpretación en abstracto y en concreto", en Chiassoni, P., Comanducci, P. y Ratti, G.B. (eds.), Larte della distinzione. Scritti per Riccardo Guastini. Vol. II, Madrid, Marcial Pons, 2018, pp. 147-64.

Poggi, F. y Sardo, A., "Do the Right Thing! - Robert Alexy and the Claim to Correctness", Rechtstheorie, 47, 2016, pp. 413-41.

Quine, V. W. O., “Translation and meaning”, en Id. Word and Object, Cambridge (Mass.), MIT Press, 1960.

Quine, V.W.O., “Two Dogmas of Empiricism”, Philosophical Review, 60, 1951, pp. 20-43. 
Alessio Sardo

Ramírez Ludeña, L., "El desvelo de la pesadilla Una respuesta a 'El escepticismo ante las reglas replanteado", Discusiones, 11, 2012, pp. 87-116.

Ramírez Ludeña, L., "Riccardo Guastini, Las Teorías de la interpretación jurídica y lo verdaderamente correcto", en Chiassoni, P., Comanducci, P. y Ratti, G.B. (eds.), Larte della distinzione. Scritti per Riccardo Guastini. Vol. II, Madrid, Marcial Pons, 2018, pp. 91-110.

Ratti, G.B., "Cornici e insiemi” en Chiassoni, P., Comanducci, P. y Ratti, G.B. (eds.), L'arte della distinzione. Scritti per Riccardo Guastini. Vol. II, Madrid, Marcial Pons, 2018, pp. 317-25.

Ruiz Manero, J., "Epílogo: interpretación jurídica y direcciones de ajuste”, Discusiones, 11, 2012, 203-19.

Russell, B., “On Denoting”, Mind, 1905, 14(4), pp. 479-493.

Russell, G., Truth in Virtue of Meaning: A Defence of the Analytic/Syntetic Distinction, Oxford, Oxford University Press, 2008.

Sbisà, M., "On Illocutionary Types", Journal of Pragmatics, 8, 1984, pp. 93-112.

Schauer, F., Playing by the Rules, Oxford, Claredon Press, 1991.

Tarello, G., Diritto, Enunciati, Usi, Bologna, Il Mulino, 1974.

Troper, M., "Anotaciones sobre Guastini”, Discusiones, 11, 2012, pp. 117-33. Troper, M., Champeil-Desplats, V., Grzegorczyk, C., La théorie des contraintes juridiques, Paris, LGDJ, 2005.

Troper, M., Pour une théorie juridique de l'Etat, Paris, PUF, 1994.

Velluzzi, V., "La distinzione tra analogia giuridica e interpretazione estensiva", en M. Manzin, P. Somaggio (eds.), Interpretazione giuridica e retorica forense. Il problema della vaghezza del linguaggio nella ricerca della verità processuale, Milano, Giuffrè, 2006, pp., 133-48.

Villa, V., Una teoria pragmaticamente orientate dell'interpretazione giuridica, Giappichelli, Torino, 2012.

Von Wright, G.H., Norm and Action. A Logical Enquiry, London, Routledge \& Kegan Paul, 1963.

Whitehead, A.N. y Russell, B., Principia Mathematica, Cambridge, Cambridge University Press, 1962.

Wittgenstein, L., Philosophical Investigations, Oxford, Basil Blackwell, 1953. 